\title{
In Memoriam Klaus Heimann
}

Klaus Heimann, Professor of Ophthalmology at the University of Cologne died on 25 June 1999, after the recurrence of a lymphoma that had been in remission. Prof. Klaus was internationally renowned for his surgical expertise in repairing eyes that had suffered perforating injuries or had retained foreign particles. He proved the value of vitrectomy and silicone for reconstructituting the injured eye and subsequently explored the use of daunomycin to inhibit postoperative proliferation. His numerous research projects included functional morphology of the choroid, hereditary vitreoretinopathies, traumatology of the retina, pathophysiology of proliferative vitreoretinopathies (PVR), surgical strategies for the treatment of PVR including intraocular application of antimetabolites (daunomycin), options of vitreous replacement, silicone oil application in complicated retinal detachment, pathophysiology and therapy of age-related macular degeneration, pigment cell transplantation of the retina, immunopathology of the pigment epithelium of the retina, retinal apoptosis, retinal neuroprosthesis (retinal implant) and intraocular visual aids.

Prof. Klaus served as President of the Club Jules Gonin, the German Ophthalmology Society, the German Retinology Society and the Association of German Professors of Ophthalmology and as a member of numerous national and international societies. Klaus served as coordinating editor of Graefe's Archive from 1990 to 1996, coeditor of Der Ophthalmologe from 1992 to 1999 and as a member of the editorial board of numerous national and international journals. Klaus published numerous chapters on vitreoretinal surgery in textbooks and handbooks of ophthalmology, and in conjunction with Peter Weidemann published "Proliferative Vitreoretinopathien" (KadenVerlag, Heidelberg, 1989) the published well over 200 scientific original contributions in peer-reviewed national and international journals. He was the recipient of numerous international honors and awards.

Seldom are we priviliged to know and share the life of such a perfectly balanced person as Klaus Heimann. He was at once a superb surgeon, an innovator, an administrator and an editor. He possessed a lively sense of humor, common sense and honesty, all combined with a kind and discriminating nature. I had the privilege of serving on the Executive Committee of the Club Jules Gonin during the six years that Klaus was President of the Club. As President he demonstrated uncommon skill and kindness in dealing with disparate voices and concerns.

Klaus is survived by his wife, $\mathrm{Su}$ sanne, and three children, Friederike, Hanno and Konrad, who were with him at the end. He will be missed by all who knew him and particularly by the members of the Club Jules Gonin who respected and treasured him.

In Westminster Abbey the epitaph to Ben Jonson says simply and eloquently "O Rare" - it is a fitting epitaph for Klaus Heimann.
D. Jackson Coleman, MD
Cornell Medical Center
New York-Presbyterian Hospital
President, Club Jules Gonin 